\title{
構造物設計における材料のせん断強度の表現法について
}

\author{
西山竜朗 ${ }^{1} \cdot$ 長谷川高士 ${ }^{2} \cdot$ 千原英司 $^{3}$
}

\section{Expression of the Shear Strength of Materials in Structural Designs}

\author{
Tatsuro Nishiyama ${ }^{1}$, Takashi Hasegawa ${ }^{2}$ and Eiji Chihara ${ }^{3}$
}

\begin{abstract}
Mohr's envelopes, which describe the shear strength of materials, are shown for structural designs, particularly the stability analyses of rockfill dams. Firstly, an effective method which has passed into oblivion is followed by a complete verification. This method provides a general analytic solution for Mohr's envelopes and is applicable to arbitrary functions which describe the results of triaxial tests. Then, the method is applied to a particular empirical criterion for rockfill materials which has been recommended over a long period of time. Suitable results are obtained from the application of such a method to a set of triaxial data for a particular rockfill material.
\end{abstract}

Keywords: Mohr's Envelope; Shear Strength; Triaxial Test; Rockfill Material; Structural Design

\section{1 はじめに}

土木構造物の設計においては，材料の強度として三軸圧 縮試験の結果が参照されることが多い。試験から得られ るMohrの包絡線は材料によって直線，曲線のいずれと もなり得るが，実用上は直線を用いて処理されることが 多いようである。

Mohr の包絡線の解析については，古く Balmer (1952) によって有効な手法が示されている. Balmer は，実験か ら得られた Mohr の応力円に対する包絡線について，任意 の関数を適用し得る方程式を導いた上で, 例解として土 の直線包絡線およびコンクリートの曲線包絡線を示して いる。一連の手法は実用上きわめて有効であり，過去に岩 盤の破壊規準への適用例がある（Hoek and Brown, 1980; Sheorey, 1997）が, 昨今では忘れ去られている感がある.

しかし，最近のフィルダムの設計で用いられている修 正震度法（建設省河川局開発課, 1991）に执いては, 安全 率の算定における必要性加ら内部摩擦角の拘束圧依存性 が重視されるようになり, 曲線包絡線の適用が提案され るに至っている.内部摩擦角の拘束圧依存性一の注目は Balmer が結論において予言した通りであり，したがって ここでBalmerによる手法を振り返って検討しておくこと には十分な意味があると思われる。

本論文では，まず第 2 章に Mohr の包絡線を表記する 上で基本となる Balmer が提示した方程式の誘導を，次い で第 3 章および第 4 章に Balmerによる直線包絡線および 曲線包絡線の具体例を示寸. なお, Balmer の例解では数 值の表示が $\mathrm{lb}$-in 単位系によっているため, それらの数值 はSI 単位系のものに改め, 全過程を再計算した上で詳細 に検討した結果を示す. また，説明不足と思われるとこ

\footnotetext{
1愛媛大学農学部准教授, Associate Professor, Faculty of Agriculture, Ehime University, 3-5-7, Tarumi, Matsuyama 790-8566, Japan (Corresponding Author) E-mail:nisiyama@agr.ehime-u.ac.jp

2京都大学名誉教授, Professor Emeritus, Kyoto University, Kitashirakawa-oiwake-cho, Sakyo-ku, Kyoto 606-8502, Japan

3 株式会社三祐コンサルタンツ九州支店取蟐役支店長, Branch ManagerDirector, Kyushu Branch, Sanyu Consultants Incorporated, 4-30-1, Saikumachi, Kumamoto 860-0041, Japan
}

ろは著者らが補足し加筆している。

その後, 第 5 章に, 修正震度法に採用されているロッ クフィル材料の曲線包絡線（松本・渡辺, 1987）について, Balmerによる方程式との対応を示寸とともに，ロックフィ ルダム築堤材料を想定した土砂混じりレキの大型三軸圧 縮試験結果への適用例を示寸。

\section{Mohr の包絡線を表す方程式}

本章では，Balmerによって提示された，Mohrの包絡線 一般を表現する媒介変数方程式を示す。

\section{1 媒介変数方程式の展開}

破壊時の最大主応力が $\sigma_{1}$, 最小主応力が $\sigma_{3}$ であるとき, 破 壊時の応力を表す Mohr 円の中心の座標は $\left(\frac{\sigma_{1}+\sigma_{3}}{2}, 0\right)$, 半径 $R$ は $\frac{\sigma_{1}-\sigma_{3}}{2}$ である.したがって，垂直応力を $\sigma$, せ 儿断灾力を $\tau$ として，Mohr 円を表す方程式が次のように 与えられる。

$$
\left(\sigma-\frac{\sigma_{1}+\sigma_{3}}{2}\right)^{2}+\tau^{2}=\left(\frac{\sigma_{1}-\sigma_{3}}{2}\right)^{2}
$$

式(1) は $\sigma_{1}$ と $\sigma_{3}$ を固定するごとに 1 個の円を表す。こ こで $\sigma_{1}$ と $\sigma_{3}$ を媒介変数と考え, さらに $\sigma_{1}$ が $\sigma_{3}$ に関し て 1 階偏微分可能な関数となっているとき, 関数の特性 （たとえば水野, 1979）から，式 (1) で表される曲線族の 包絡線，すなわち Mohr の包絡線が次のように表される.

$$
\begin{array}{r}
\sigma=\sigma_{3}+\frac{\sigma_{1}-\sigma_{3}}{\frac{\partial \sigma_{1}}{\partial \sigma_{3}}+1} \\
\tau=\frac{\sigma_{1}-\sigma_{3}}{\frac{\partial \sigma_{1}}{\partial \sigma_{3}}+1} \sqrt{\frac{\partial \sigma_{1}}{\partial \sigma_{3}}}
\end{array}
$$






図 1: Mohr の応力円図 (Balmer, 1952; 表記を改変)

これらの媒介変数方程式が Mohr の包絡線一般を表現す る基本となり， $\sigma_{1}-\sigma_{3}$ 関係が代入されるごとに特定の材 料の破壊規準を表す.

式(1)〜(3)によるMohr の応力円図を図 1 に示す. 図 1 は, 式 (2)および式 (3) に含まれる諸量の図解を与える. 図 1 において $\triangle \mathrm{AHB}$ の二辺の比 $\frac{\mathrm{HA}}{\mathrm{BH}}=\tan \alpha$ に注目する と, 式(2) と式(3) から次の比を考えることができる.

$$
\frac{\tau}{\sigma-\sigma_{3}}=\tan \alpha=\sqrt{\frac{\partial \sigma_{1}}{\partial \sigma_{3}}}
$$

ここに， $\alpha$ は破壊面が最大主応力面となす角すなわち破

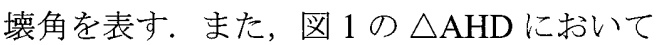

$$
2 \alpha=\phi+90^{\circ}
$$

が成り立つ. 式 (4) と式 (5) から，Mohr の包絡線の傾き $\tan \phi$ が次式を満たすことがわかる。

$$
\frac{d \tau}{d \sigma}=\tan \phi=\frac{\frac{\partial \sigma_{1}}{\partial \sigma_{3}}-1}{2 \sqrt{\frac{\partial \sigma_{1}}{\partial \sigma_{3}}}}
$$

ここに, $\phi$ は内部摩擦角を表す.

\section{2 特定の問題への適用}

前節の方程式を特定の問題に用いるときには, 次の二通 りの手順が考えられる。

手順 I: まず $\sigma-\tau$ 関係を表す関数の形を定め, 曲線近 似法によりこの関数で $\sigma-\tau$ 関係を近似する. 次 いで， $\sigma-\tau$ 関係を表寸定数を用いて， $\sigma_{1}-\sigma_{3}$ 関 係を表記する。

手順 II：まず $\sigma_{1}-\sigma_{3}$ 関係を表す関数の形を定め, 曲線近 似法によりこの関数で $\sigma_{1}-\sigma_{3}$ 関係を近似する. 次いで， $\sigma_{1}-\sigma_{3}$ 関係を表す定数を用いて， $\sigma-\tau$ 関係を表記する.
表 1: 土の三軸圧縮試験結果 (Balmer, 1952; 単位を改変)

\begin{tabular}{cc}
\hline 側圧, $\sigma_{3}, \mathrm{kPa}$ & 軸圧, $\sigma_{1}, \mathrm{kPa}$ \\
\hline 73.1 & 407.5 \\
130.3 & 564.7 \\
206.8 & 895.6 \\
278.5 & $1,054.2$ \\
539.2 & $2,027.7$ \\
\hline$n=5$; 有効応力を表示.
\end{tabular}

ここに, $\sigma-\tau$ 関係とはすなわち Mohr の包絡線であり，ま た $\sigma_{1}$ と $\sigma_{3}$ は三軸圧縮試験にお污る測定值そのものであ る.いずれの手順においても, 関数が試験結果を適切に 表すこと，ならびに演算が十分に容易であることが必要 である。

\section{3 直線包絡線}

本章では Balmerによる直線包絡線の例解を示す，表 1 に 示寸土の三軸圧縮試験結果に対し, まず 3.1 節と 3.2 節に おいて 2.2 節の手順 Iによる解を示し，次いで 3.3 節にお いて手順 IIによる解に触れる.

\section{1 包絡線を表す関数}

まず，Mohr の包絡線が粘着力 $c$ および内部摩擦角 $\phi$ を定 数として

$$
\tau=c+\sigma \tan \phi
$$

で表されると仮定する。すなわち，以下では一例として 式 (7)が成り立つ場合について,Mohrの包絡線一般を表 す式(2)および式 (3) を適用する.

$$
\text { ここで, 式 (6) を } \sqrt{\frac{\partial \sigma_{1}}{\partial \sigma_{3}}} \text { について解くと次式が得ら }
$$
れる。

$$
\sqrt{\frac{\partial \sigma_{1}}{\partial \sigma_{3}}}=\tan \phi+\sqrt{1+\tan ^{2} \phi}
$$


式(8)を式(2)および式(3)に代入すると, 次式が得られる.

$$
\begin{aligned}
\sigma & =\frac{1}{2}\left\{\sigma_{1}(1-\sin \phi)+\sigma_{3}(1+\sin \phi)\right\} \\
\tau & =\frac{\sigma_{1}-\sigma_{3}}{2} \cos \phi
\end{aligned}
$$

なお，図 1 において Mohr 円の中心，半径 $R$ および $\triangle \mathrm{AHD}$ に注目寸ると, これらの関係が容易に確認される.

式 (7) に式 (9) と式 (10) を代入して $\sigma$ と $\tau$ を消去する と, 式 (7) に対応する $\sigma_{1}-\sigma_{3}$ 関係が次のように得られる.

$$
\sigma_{1}=\frac{2 c \cos \phi}{1-\sin \phi}+\frac{1+\sin \phi}{1-\sin \phi} \sigma_{3}
$$

式(7)および式(9)〜(11)はいずれも，Mohr-Coulombの 破壊規準に関して一般に知られる式（たとえば石原, 1988) と一致する。

\section{2 測定値の近似}

最小二乗法（たとえば Ang and Tang, 1977）によれば，式 (7) における定数 $\tan \phi$ および $c$ の最確值が次のように与 えられる。

$$
\begin{aligned}
\tan \phi & =\frac{n \sum \sigma \tau-\sum \sigma \sum \tau}{n \sum \sigma^{2}-\left(\sum \sigma\right)^{2}} \\
c & =\frac{\sum \tau-\tan \phi \sum \sigma}{n}
\end{aligned}
$$

ただし， $n$ は試験個数， $\sum$ は 1 から $n$ までの総和を表す.

表 1 の試験結果は $\sigma_{1}$ と $\sigma_{3}$ の組合せとして与えられて いる.したがって，測定值をそのまま代入できるよう， と $\tau$ で表記されている式(12) および式 $(13)$ を $\sigma_{1}$ と $\sigma_{3} に$ よる表記に直しておくと，便宜上都合がよい。

統計においてしばしば用いられる量である，平均值か らの隔たり量を $\delta$ として, 次のような表記が得られる.

$$
\begin{gathered}
n \sum \delta_{\sigma_{1}}{ }^{2}=n^{2}{\overline{s_{\sigma_{1}}}}^{2}=n \sum{\sigma_{1}}^{2}-\left(\sum \sigma_{1}\right)^{2} \\
n \sum \delta_{\sigma_{3}}{ }^{2}=n^{2}{\overline{s_{\sigma_{3}}}}^{2}=n \sum{\sigma_{3}}^{2}-\left(\sum \sigma_{3}\right)^{2} \\
n \sum \delta_{\sigma_{1}} \delta_{\sigma_{3}}=n \sum \sigma_{1} \sigma_{3}-\sum \sigma_{1} \sum \sigma_{3}
\end{gathered}
$$

なお， $\bar{s}$ は標準偏差を表し， $\bar{s}$ おび $\delta$ の下添字は統計の 対象とする量を表す。これらの式は，元の測定值を平均 值に関する量へと変換している.

さらに，これらの表記を用いて次の量を定義する。

$$
\begin{aligned}
& a^{2}=\frac{\sum \delta_{\sigma_{1}}{ }^{2}}{\sum \delta_{\sigma_{3}}{ }^{2}} \\
& b^{2}=\frac{\sum \delta_{\sigma_{1}} \delta_{\sigma_{3}}}{\sum \delta_{\sigma_{3}}{ }^{2}}
\end{aligned}
$$

ここに，值が異なる複数個の $\sigma_{3}$ の測定値が得られている ならば両式右辺の分母の值は正である. したがって $a^{2} \geq 0$ であり, また $\sigma_{3}$ の増加に対して $\sigma_{1}$ が減少しないならば $b^{2} \geq 0$ である. このとき $a, b$ が各々 $a^{2}, b^{2}$ の正の平方根 として得られ, 以下本章ではこれらの条件が満たされて いるものとする. なお， $\sigma_{3}$ の増加に対して $\sigma_{1}$ の増加が より小さくないならば，さらに $a^{2} \geq 1$ および $b^{2} \geq 1$, す なおち $a \geq 1$ および $b \geq 1$ が成り立つ.



図 2: 土の破壊規準 (Balmer, 1952; 表記を改変)

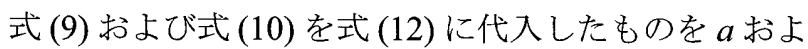
び $b$ を用いて表記し，それを $\sin \phi$ について解くと次式が 得られる.

$$
\sin \phi=\frac{a-1}{a+1}
$$

上式からさらに, $\tan \phi$ が主応力で表記された次式が得 られる。

$$
\tan \phi=\frac{a-1}{2 \sqrt{a}}
$$

式(9), 式(10)および式(20)を式(13)に代入すると, $c$ の主応力による表記が次のように得られる。

$$
c=\frac{\sum \sigma_{1}-a \sum \sigma_{3}}{2 n \sqrt{a}}
$$

手順 Iに従い，Mohrの包絡線を表す過程で得られた定 数を用いて, 主応力の関係を表記しておく. $a$ を用いて式 (11)を表記すると, 次のようになる.

$$
\sigma_{1}=2 c \sqrt{a}+a \sigma_{3}
$$

式 (22) は, 式 (7) に最小二乗法を適用して得られた解で ある.式(22) は三軸圧縮試験における破壊時の軸圧一側 圧関係を表し，図示すると後掲の図 3 に類似した図が得 られる。ただし，Mohrの包絡線が直線である場合は，図 3 の曲線が直線となる。

図 2 は Mohrの包絡線として式 (7) を適用した結果であ り，定数の值の算定は本節の手順によった。図中の直線 は表 1 の測定值に関する Mohr 円の包絡線を十分に近似 しており，前節冒頭における仮定は妥当であったことが わかる。

Balmer は，近似直線を定めた後には，近似直線の確か らしさを評価するための信頼限界を算出しておくことが 望ましいと述べている。ここでは誘導の過程については 割愛し, 結果のみを次に示しておく.

$$
\vec{s}_{\tau_{\tau \sigma}^{\prime}}^{2}=\frac{a-b^{2}}{2(n-2)}\left\{{\overline{s_{\sigma_{3}}}}^{2}+\frac{(a+1)^{2} \delta_{\sigma}{ }^{2}}{2 a\left(a+b^{2}\right)}\right\}
$$

ここに， $\vec{s}_{\tau_{\tau \sigma}^{\prime}}^{2}$ は推定せん断強度 $\tau^{\prime}$ の標準䛊差を表し，平 均との差がその大きさ以下である值域は，考慮す心゙き起 こり得る全事象に対する $68 \%$ の確率を与える。標本の大 きさが大きい場合には，值域を標準誤差の 2 倍にすると 対応する確率が $95 \%$ に, 3 倍では 99\%となる.ただし, 標 本数が 30 末満の場合には，その確率は若干減少する。物 性試験を取り扱う場合には標準誤差の 2 倍を信頼限界と することが多く, 図 2 には信頼限界 $2 \vec{s}_{\tau_{\tau \sigma}^{\prime}}^{2}$ を合わせて示し ている. 


\section{3 近似の手順による解の相違}

前節における近似では手順 I を用いたが, 最初に表 1 の $\sigma_{1}-\sigma_{3}$ 関係が式(11) で表されることを仮定し手順 II によ ることとした場合には，最小二乗法を式 (7) ではなく式 (11) に適用して測定值を近似することとなり，結果とし て式(22) とは若干異なる次式が得られる。

$$
\sigma_{1}=2 c b+b^{2} \sigma_{3}
$$

ここに， $b$ は式(18) で定義された量である.式(24) は式 (11)を最小二乗法で解いた結果であり，式(9) と式(10)を 参照して変形すると, 式(7) 中の $\tan \phi$ および $c$ は次のよ うになる。

$$
\begin{aligned}
\tan \phi & =\frac{b^{2}-1}{2 b} \\
c & =\frac{\sum \sigma_{1}-b^{2} \sum \sigma_{3}}{2 n b}
\end{aligned}
$$

近似の手順による解の相違は, 最小二乗法により最小 化した量が異なるために生じる。既述したが，実際の問 題一適用する際には, より適切な, 所望量をより容易に 算定する手順を選抧する。

式 (24) の標準誤差 $\vec{s}_{\sigma_{1}^{\prime} \sigma_{1} \sigma_{3}}^{2}$ は, 式 (7) の標準誤差である 式 (23)に類似して, 次のように与えられる.

$$
\vec{s}_{\sigma_{1} \sigma_{1} \sigma_{3}}^{2}=\frac{a^{2}-b^{4}}{n-2}\left(\bar{s}_{\sigma_{3}}{ }^{2}+\delta_{\sigma_{3}}{ }^{2}\right)
$$

\section{4 曲線包絡線}

本章では Balmer による曲線包絡線の例解を示す．表 2 に 示すコンクリートの三軸圧縮試験結果に対し，手順 II に よる解を示す。

\section{1 包絡線を表す関数}

まず，軸圧と側圧の関係が， $a, b$ および $c$ を定数として

$$
\sigma_{3}=b \sigma_{1}^{c}+a
$$

で表されると仮定する。すなわち，以下では一例として 式 (28) が成り立つ場合について, Mohr の包絡線一般を 表す式 (2) および式(3) を適用する。なお, 式(28) 中の定 数は, 本章以外において同じ文字で表された量と無関係 である。

表 2 の離散的な測定值を扱うために, 式(28)の導関数 を有限増分量によって近似すると, 次式が得られる。

$$
\frac{\Delta \sigma_{1}}{\Delta \sigma_{3}}=\frac{1}{b c \sigma_{1}^{c-1}}
$$

式(2) と式(3)に式(28)を代入し，さらに $\frac{\partial \sigma_{1}}{\partial \sigma_{3}}$ の代わ りに $\frac{\Delta \sigma_{1}}{\Delta \sigma_{3}}$ を用いることとして式(29) を代入すると， $\sigma_{3}$ が消去され，次のように $\sigma_{1}$ を媒介変数とする Mohr の包 絡線の方程式が得られる。

$$
\begin{aligned}
\sigma & =\frac{b(c+1) \sigma_{1}{ }^{c}}{1+b c \sigma_{1}{ }^{c-1}}+a \\
\tau & =\frac{\sigma_{1}-a-b \sigma_{1}{ }^{c}}{1+b c \sigma_{1}{ }^{c-1}} \sqrt{b c \sigma_{1}^{c-1}}
\end{aligned}
$$

これらの式は， $\sigma_{1}-\sigma_{3}$ 関係が式 (28) に従う場合の Mohr の包絡線を表す。
表 2: コンクリートの三軸圧縮試験結果 (Balmer, 1952; 単 位を改変)

\begin{tabular}{rc}
\hline 側压, $\sigma_{3}, \mathrm{kPa}$ & 軸圧 $\sigma_{1}, \mathrm{kPa}$ \\
\hline 0 & 23,856 \\
0 & 24,200 \\
0 & 25,855 \\
6,895 & 68,602 \\
6,895 & 69,636 \\
6,895 & 76,186 \\
17,237 & 110,039 \\
17,237 & 118,865 \\
17,237 & 122,174 \\
34,474 & 168,093 \\
34,474 & 174,022 \\
34,474 & 176,573 \\
51,710 & 222,561 \\
51,710 & 224,491 \\
51,710 & 228,766 \\
68,947 & 267,790 \\
68,947 & 272,754 \\
68,947 & 280,545 \\
103,421 & 359,972 \\
103,421 & 365,902 \\
103,421 & 374,382 \\
137,894 & 450,224 \\
137,894 & 465,599 \\
137,894 & 468,219 \\
172,368 & 512,000 \\
172,368 & 538,821 \\
172,368 & 543,096 \\
\hline$n=27 ;$ 増分については $n=24$.
\end{tabular}

\section{2 測定値の近似}

任意の定数 $a, b$ および $c$ の值は, 測定值に対して最小二 乗法を適用することにより定められる．その算定過程を 二段階に分けると，前章の直線包絡線の場合之概䄈同じ ようにこれらの值を定めることができる。

まず, $c$ の最確值を求める. 式 (29) 両辺の対数をとる と次式が得られる.

$$
\log \frac{\Delta \sigma_{1}}{\Delta \sigma_{3}}=-\log (b c)-(c-1) \log \sigma_{1}
$$

なお，本論文中の対数表記は，すべて常用対数を表す。 $\log \frac{\Delta \sigma_{1}}{\Delta \sigma_{3}}$ と $\log \sigma_{1}$ を変数, $\log (b c)$ と $(c-1)$ を任意の定数 と考えれば，式 (32) は線形として取り扱うことができ， 式(12)に類似した次式が得られる.

$$
-(c-1)=\frac{n \sum \log \sigma_{1} \log \frac{\Delta \sigma_{1}}{\Delta \sigma_{3}}-\sum \log \sigma_{1} \sum \log \frac{\Delta \sigma_{1}}{\Delta \sigma_{3}}}{n \sum\left(\log \sigma_{1}\right)^{2}-\left(\sum \log \sigma_{1}\right)^{2}}
$$

次いで， $a$ と $b$ の最確值を求める。 $c$ が既知となったこ とにより式(28)を $\sigma_{1}{ }^{c}$ と $\sigma_{3}$ の線形関係とみなし, 直線包 絡線の場合と同様に最小二乗推定值を算定する。式 (12) および式(13) に類似して,$b$ および $a$ が次のように与え 


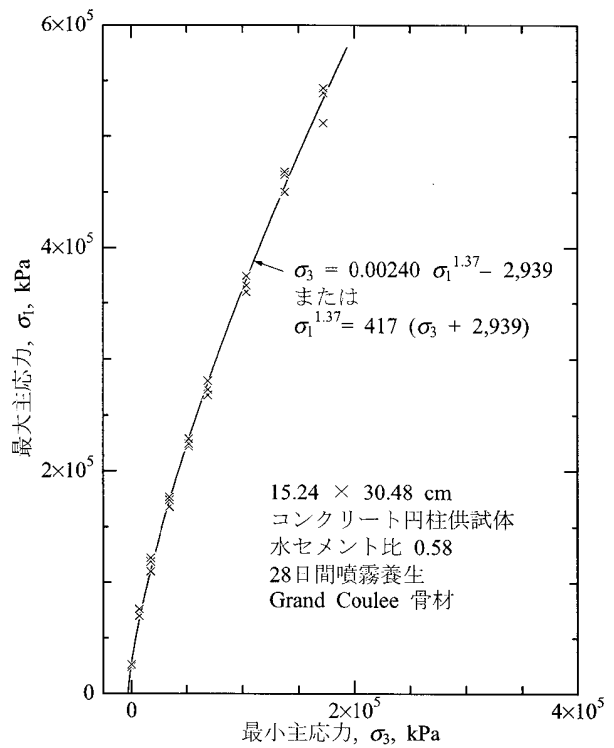

図 3: コンクリートの三軸圧縮試験結果 (Balmer, 1952; 単 位を改変)



図 4: コンクリートの破壊規準 (Balmer, 1952; 表記を改変)

られる。

$$
\begin{aligned}
& b=\frac{n \sum \sigma_{1}^{c} \sigma_{3}-\sum \sigma_{1}^{c} \sum \sigma_{3}}{n \sum\left(\sigma_{1}^{c}\right)^{2}-\left(\sum \sigma_{1}^{c}\right)^{2}} \\
& a=\frac{\sum \sigma_{3}-b \sum \sigma_{1}^{c}}{n}
\end{aligned}
$$

表 2 の測定值に対して式 (33) (35) を適用すると $a=$ $-2,939, b=0.00240, c=1.373$ が得られ，これらの算 定結果を図示すると図 3 および図 4 のようになる。

必要であれば，式 $(28)$ をつの変数 $\sigma_{3}$ と $\sigma_{1}^{c}$ に関し て線形と考えることにより，直線包絡線の場合と同様に， 式 (28) で表される曲線に対する信頼限界を算定すること ができる. 略記のため $\sigma_{1}{ }^{c}=z$ とすると，推定された $\sigma_{3}$ の標準誤差は次のようになる。

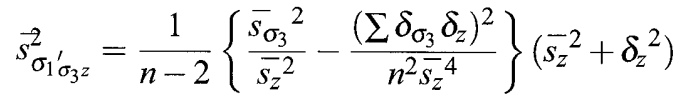

\section{5 ロックフィル材料の曲線包絡線}

本章では，著者らによるロックフィル材料への曲線包絡 線の適用例を示す.

\section{1 包絡線を表す関数}

de Mello (1977) は，ロックフィル材料について，内部摩擦 角の拘束圧依存性に注目して曲線包絡線を示し，その曲 線包絡線を用いてダム堤体の安定計算を行い，深部のす ベりについて直線包絡線を用いた場合と異なる安全率が 算定されたことを報告している. Charles and Watts (1980) は, de Mello が示した曲線包絡線を次のように表記した。

$$
\tau=A \sigma^{b}
$$

ここに，Aおよび $b$ は任意の定数を表す．なお，定数 $b$ に ついて，本章以外において同じ文字で表された量とは無 関係である。

de Mello が示した曲線包絡線採用の必要性を鑑み，松 本・渡辺 (1987) は，三軸圧縮試験結果である $\sigma_{1}-\sigma_{3}$ 関係 を表す経験則を次のように示した。

$$
\sigma_{1}=n_{0} \sigma_{3}^{m}
$$

ここに， $m$ および $n_{0}$ は任意の定数である。なお，松本・ 渡辺は，両主応力を大気圧で正規化することにより $m$ お よび $n_{0}$ の值が単位系に依存しないよう配慮しているが, ここでは表記簡略化のため上式を用いることとする。

式 (38) から次式が成り立つ.

$$
\frac{\partial \sigma_{1}}{\partial \sigma_{3}}=m n_{0} \sigma_{3}^{m-1}
$$

式 (38) および式 (39) を式 (2) および式 (3) に代入する 之, 次の式が得られる.

$$
\begin{aligned}
\sigma & =\frac{(m+1) n_{0} \sigma_{3}{ }^{m}}{m n_{0} \sigma_{3}{ }^{m-1}+1} \\
\tau & =\frac{n_{0} \sigma_{3}{ }^{m}-\sigma_{3}}{m n_{0} \sigma_{3}{ }^{m-1}+1} \sqrt{m n_{0} \sigma_{3}^{m-1}}
\end{aligned}
$$

これらの式は帮質的に，Balmerによる誘導とは別に松本・ 渡辺によって導かれたものと同じである， $\sigma_{3}$ の值を上式 に代人することにより，各測定值に対応する破壊面上の 垂直忘力 $\sigma$ およびせん断忘力 $\tau$ が得られる.

以上では手順 II を採用したことになるが，曲線包絡線 については一般に $\sigma-\tau$ 関係を表す陽関数の誘導が困難で ある。しかし，安定計算においては一般に，仮定された すべり面上で算定された垂直応力に対応するせん断強度 の值が必要とされるため, $\sigma-\tau$ 関係が陽関数として表さ れていることが強く望まれる，そこで，松本・渡辺は，式 (40) および式 (41) から得られた $\sigma$ および $\tau$ の值に対して さらに式 (37) による近似を適用して $A$ と $b$ の值を定め, せん断強度を垂直応力の陽関数として表した。

\section{2 ロックフィルダム築堤材料への適用}

表 3 の左側 2 列に，ロックフィルダム築堤材料を想定した 材料に対する大型三軸圧縮試験の結果を示す。なお，こ れらの測定值は，最大粒径 $63 \mathrm{~mm}$ の土砂混じりレキにつ いて，直径 $300 \mathrm{~mm}$ 円柱供試体に対する圧密排水試験か ら得られた。

式(38)および式 (37)による近似の際には，各々の式に ついて両辺の対数をとった次の式を用いればよい.

$$
\begin{aligned}
\log \sigma_{1} & =\log n_{0}+m \log \sigma_{3} \\
\log \tau & =\log A+b \log \sigma
\end{aligned}
$$


表 3: ロックフィル材料の三軸圧縮試験結果

\begin{tabular}{|c|c|c|}
\hline $\begin{array}{c}\text { 側圧 } \\
\sigma_{3}, \mathrm{kPa}\end{array}$ & $\begin{array}{c}\text { 軸圧 } \\
\sigma_{1}, \mathrm{kPa}\end{array}$ & $\begin{array}{c}\text { 内部摩擦角 } \\
\phi, \text { 度 }\end{array}$ \\
\hline 49 & 315.56 & 43.6 \\
\hline 98 & 573.30 & 41.3 \\
\hline 294 & $1,462.16$ & 37.9 \\
\hline 490 & $2,228.52$ & 36.3 \\
\hline 686 & $2,945.88$ & 35.3 \\
\hline 882 & $3,626.98$ & 34.5 \\
\hline 1,176 & $4,850.02$ & 33.7 \\
\hline
\end{tabular}

$n=7$; 有効応力を表示.

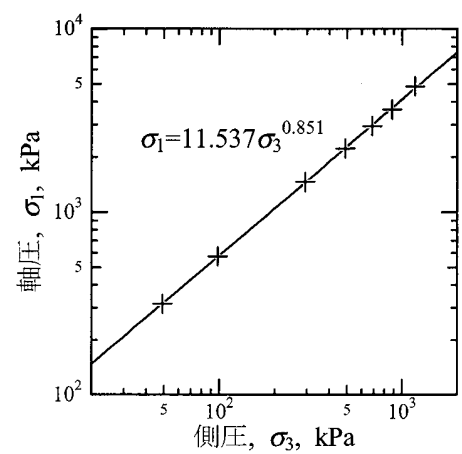

図 5: 軸圧一側圧関係

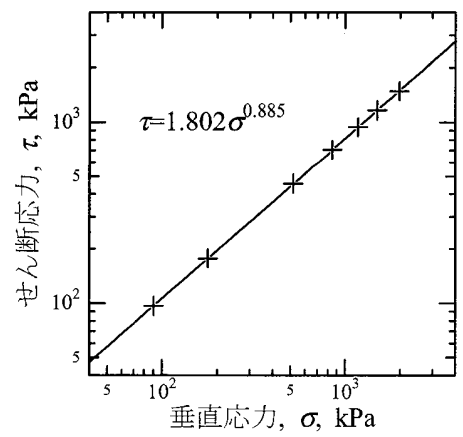

図 6: 破壊面上の垂直応力一せん断応力関係

式(42)については $\log \sigma_{1}$ と $\log \sigma_{3}$ を変数, $\log n_{0}$ と $m$ を定 数と考えることにより，式 (43)については $\log \tau$ と $\log \sigma$ を変数, $\log A$ と $b$ を定数と考えることにより, 線形の最 小二乗法を適用することができる.

式(42) による近似の結果 $\left(m=0.851, n_{0}=11.537\right)$ を図 5 に, 式 (43) による近似の結果 $(A=1.802, b=0.885)$ を 図 6 に, Mohrの包絡線を図 7 に示す.

ここに，内部摩擦角 $\phi$ が次のように与えられる.

$$
\tan \phi=\frac{d \tau}{d \sigma}=b A \sigma^{b-1}
$$

表 3 の右側 1 列に，式(44) から得られた $\phi$ の值を示す. これらの值から，ここで採用された曲線包絡線が $\phi$ の拘 束圧依存性を表現していることがわかる。



図 7: ロックフィル材料の破壊規準

6 おわりに

Balmer は，直線，曲線のいずれをも表し得る一般性を持 つ包絡線を示した上で，第 3 章に示した例のように直線 で十分に近似される場合には，便宜のため直線包絡線を 用いるべきとの見解を述べている。ロックフィル材料に ついても，建設省河川局開発課 (1991) は式 (37) で表され る曲線包絡線とともに粘着力の有無 2 通りの直線包絡線 を示し，いずれか適切なものを採用するよう指針を与え ている.

しかし，ごく最近においても，山口ら (2007) が内部摩 擦角の拘束圧依存性に対する考慮の必要性を鑑み，設計 上の必要から垂直応力域を分割して直線包絡線を用いた 検討を行っている。したがって，ロックフィル材料の強 度評価は，曲線包絡線による評価が望ましい場合に相当 すると考えられる。

\section{引用文献}

[1] Ang, A.H-S. and Tang, W.H. (1977): 土木・建築のための確 率・統計の基礎，伊藤 學・亀田弘行訳，丸善， $412 \mathrm{p}$.

[2] Balmer, G. (1952): A general analytic solution for Mohr's envelope, Proceedings, American Society for Testing Materials, 52, pp.1260-1271.

[3] Charles, J.A. and Watts, K.S. (1980): The influence of confining pressure on the shear strength of compacted rockfill, Géotechnique, 30(4), pp.353-367.

[4] de Mello, V.F.B. (1977): Reflections on design decisions of practical significance to embankment dams, Géotechnique, 27(3), pp.279-355.

[5] 石原研而 (1988): 土質力学, 丸善, $297 \mathrm{p}$.

[6] Hoek, E. and Brown, E.T. (1980): Empirical strength criterion for rock masses, Journal of the Geotechnical Engineering Division, Proceedings of the American Society of Civil Engineers, 106(GT9), pp.1013-1035.

[7]建設省河川局開発課 監修 (1991): フィルダムの耐震設計指 針（案），国土開発技術研究センター，95 p.

[8] 松本徳久 ・ 渡辺和夫 (1987): ロック材のせん断強度, 土と 基礎，35(12), pp.49-54.

[9] 水野克彦 編 (1979): 新講 解析学, 第 2 版, 学術図書出版 社, $312 \mathrm{p}$.

[10] Sheorey, P.R. (1997): Empirical Rock Failure Criteria, A.A. Balkema, $176 \mathrm{p}$

[11] 山口嘉一・佐藤弘行・中村洋祐・林 直良・倉橋 宏 (2007): 低拘束圧条件下におけるロック材料強度の評価，ダム技術, 249 , pp.22-37.

この論文の公開の質疑または討議は2008年12月31日 まで受付けます。 